\title{
A New High-Efficiency Single-Phase Transformerless PV Inverter Topology
}

\author{
Tamás Kerekes, Member, IEEE, Remus Teodorescu, Senior Member, IEEE, Pedro Rodríguez, Member, IEEE, \\ Gerardo Vázquez, Student Member, IEEE, and Emiliano Aldabas, Member, IEEE
}

\begin{abstract}
There is a strong trend in the photovoltaic inverter technology to use transformerless topologies in order to acquire higher efficiencies combining with very low ground leakage current. In this paper, a new topology, based on the H-bridge with a new ac bypass circuit consisting of a diode rectifier and a switch with clamping to the dc midpoint, is proposed. The topology is simulated and experimentally validated, and a comparison with other existing topologies is performed. High conversion efficiency and low leakage current are demonstrated.
\end{abstract}

Index Terms-Leakage current, parasitic capacitance, switching converter.

\section{INTRODUCTION}

$\mathbf{P}$ HOTOVOLTAIC (PV) inverters become more and more widespread within both private and commercial circles. These grid-connected inverters convert the available direct current supplied by the PV panels and feed it into the utility grid. According to the latest report on installed PV power, during 2007 , there has been a total of $2.25 \mathrm{GW}$ of installed PV systems, out of which the majority (90\%) has been installed in Germany, Spain, U.S., and Japan. At the end of 2007, the total installed PV capacity has reached $7.9 \mathrm{GW}$ of which around $92 \%$ is grid connected [1].

There are two main topology groups used in the case of grid-connected PV systems, namely, with and without galvanic isolation [2]. Galvanic isolation can be on the dc side in the form of a high-frequency dc-dc transformer or on the grid side in the form of a big bulky ac transformer. Both of these solutions offer the safety and advantage of galvanic isolation, but the efficiency of the whole system is decreased due to power losses in these extra components. In case the transformer is omitted, the efficiency of the whole PV system can be increased with an extra $1 \%-2 \%$. The most important advantages of transformerless PV systems can be observed in Fig. 1, such as higher efficiency and smaller size and weight compared to the PV systems that have galvanic isolation (either on the dc or ac side).

Fig. 1 has been made from the database of more than 400 commercially available PV inverters, presented in a commercial magazine about PV systems [3]. Transformerless

Manuscript received December 19, 2008; revised April 6, 2009; accepted May 14, 2009. Date of publication June 5, 2009; date of current version December 10, 2010.

T. Kerekes and R. Teodorescu are with the Institute of Energy Technology, Aalborg University, Aalborg, Denmark.

P. Rodríguez, G. Vázquez, and E. Aldabas are with the Technical University of Catalonia (UPC), Barcelona, Spain.

Color versions of one or more of the figures in this paper are available online at http://ieeexplore.iee.org.

Digital Object Identifier 10.1109/TIE.2009.2024092
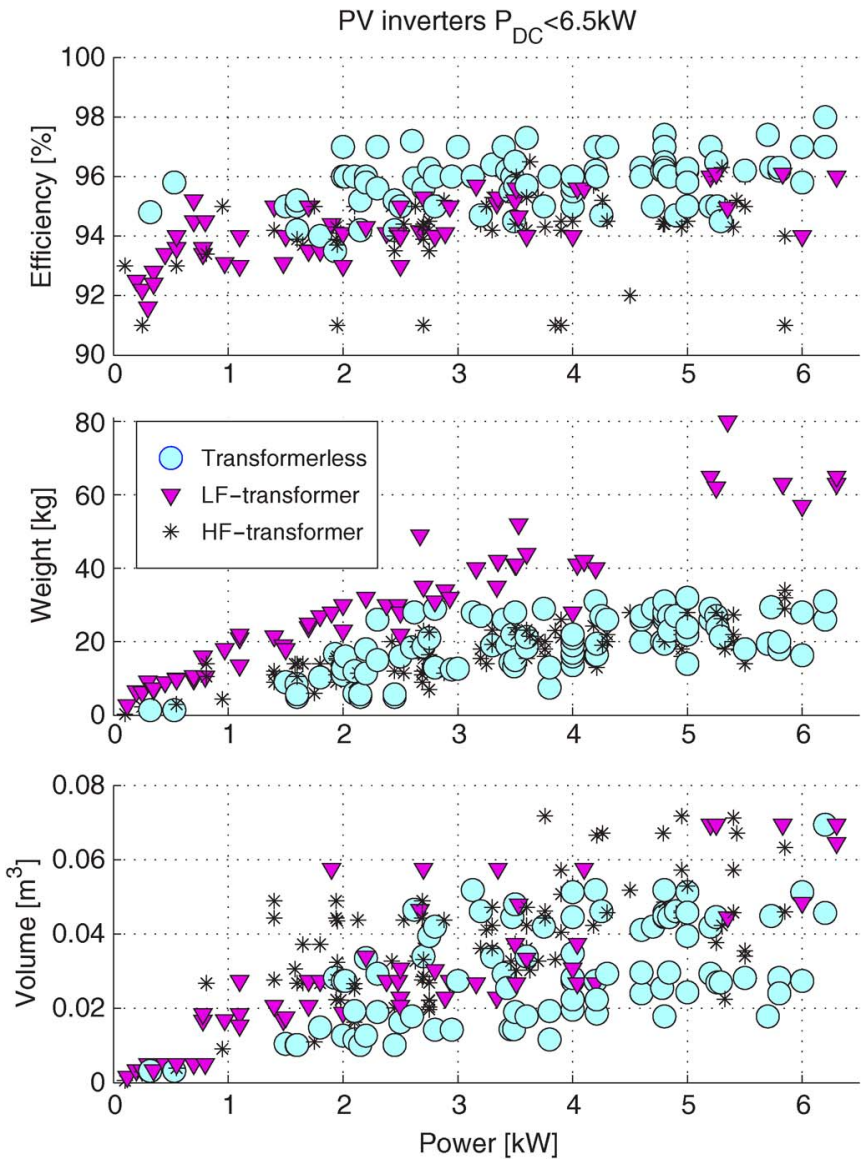

Fig. 1. Advantages and drawback of different inverter topologies.

inverters are represented by the dots (transformerless), the triangles represent the inverters that have a low-frequency transformer on the grid side (LF-transformer), and last, the stars represent the topologies, including a high-frequency dc-dc transformer (HF-transformer), adding a galvanic isolation between the PV and grid. The conclusion drawn from these graphs is that transformerless inverters have higher efficiency and smaller weight and size than their counterparts with galvanic separation.

Transformerless PV inverters use different solutions to minimize the leakage ground current and improve the efficiency of the whole system, an issue that has previously been treated in many papers [4]-[11].

In order to minimize the ground leakage current through the parasitic capacitance of the PV array, several techniques have been used. 
One of them is to connect the midpoint of the dc-link capacitors to the neutral of the grid, like the half-bridge, neutral point clamped (NPC), or three-phase full bridge with a split capacitor topology, thereby continuously clamping the PV array to the neutral connector of the utility grid. Half-bridge and NPC type of converters have very high efficiency, above $97 \%$, as shown in [6]. Furthermore, the topology proposed in [6] reduces the dc current injection, which is an important issue in the case of transformerless topologies and is limited by different standards. The noninjection of dc current into the grid is topologically guaranteed by adding a second capacitive divider to which the neutral terminal of the grid is connected. An extra control loop is introduced that compensates for any dc current injection, by controlling the voltage of both capacitive dividers to be equal. A disadvantage of half-bridge and NPC type of converters is that, for single-phase grid connection, they need a $700-\mathrm{V}$ dc link.

Another solution is to disconnect the PV array from the grid, in the case of H-bridge (HB) inverters, when the zero vector is applied to the load (grid). This disconnection can be done either on the dc side of the inverter (like the topology from [4] and H5 topology from Solar Technologies AG [13]) or on the ac side (like the Highly Efficient and Reliable Inverter Concept (HERIC) topology from Sunways [12]).

In this paper, a new topology called HB zero-voltage state rectifier (HB-ZVR) is proposed where the midpoint of the dc link is clamped to the inverter only during the zero-state period by means of a diode rectifier and one switch.

In Section II, a comparison of known transformerless topologies and the HB-ZVR is performed using simulation, focusing on the voltage to earth and ground leakage current. In Section III, experimental results are shown, confirming the simulations. Section IV presents the efficiency curve of the compared topologies.

\section{TRANSFORMERLESS TOPOLOGY ANALYSIS}

As discussed in previous works [8], [11], the common-mode voltage generated by a topology and modulation strategy can greatly influence the ground leakage current that flows through the parasitic capacitance of the PV array. Generally, the utility grid does not influence the common-mode behavior of the system, so it can be concluded that the generated commonmode voltage of a certain inverter topology and modulation strategy can be shown using a simple resistor as load. Therefore, in the case of simulations, only a resistive load is used, and the common-mode voltage is measured between the $\mathrm{dc}+$ terminal of the dc source and the grounded middle point of the resistor as shown in Fig. 2.

In the following, simulation results obtained using Matlab Simulink with the PLECS toolbox are shown. The simulation step size is $0.1 \mu \mathrm{s}$, with an $8-\mathrm{kHz}$ switching frequency.

Simulation parameters:

$L_{f}=1.8 \mathrm{mH} \quad$ filter inductance;

$C_{f}=2 \mu \mathrm{F} \quad$ filter capacitance;

$R=7.5 \Omega \quad$ load resistance;

$V_{\mathrm{dc}}=350 \mathrm{~V} \quad$ input dc voltage;

$C_{\mathrm{dc}}=250 \mu \mathrm{F} \quad$ dc-link capacitance;

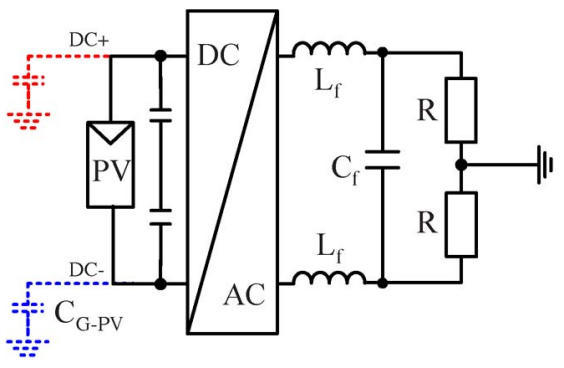

Fig. 2. Test setup used for common-mode voltage measurement.

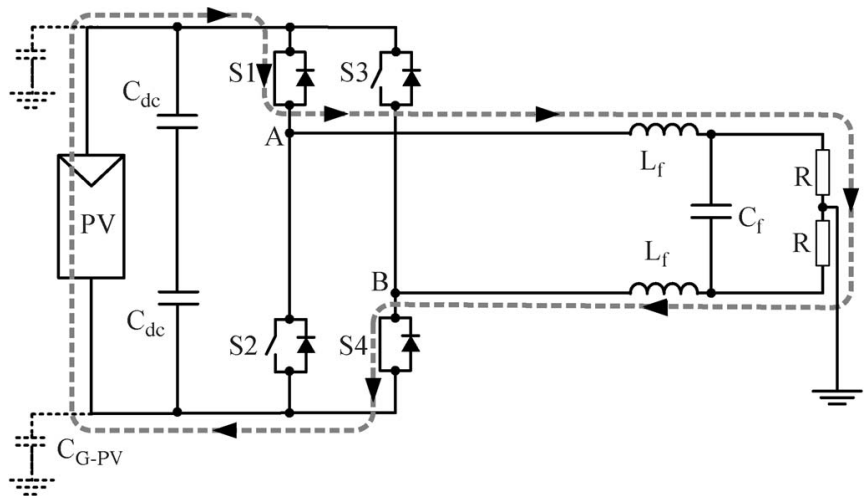

Fig. 3. HB-Unip topology: Active vector applied to load, using S1 and S4 for positive voltage.

$C_{\mathrm{G}-\mathrm{PV}}=100 \mathrm{nF} \quad$ parasitic capacitance of $\mathrm{PV}$ array;

$F_{\mathrm{Sw}}=8 \mathrm{kHz} \quad$ switching frequency for all cases except that the switching frequency for unipolar pulsewidth modulation (PWM) has been chosen to be $F_{\mathrm{sw}}=4 \mathrm{kHz}$, so the output voltage of the inverter has the same frequency for all cases.

\section{A. HB With Unipolar Switching}

Most single-phase HB inverters use unipolar switching in order to improve the injected current quality of the inverter, which is done by modulating the output voltage to have three levels with twice the switching frequency. Moreover, this type of modulation reduces the stress on the output filter and decreases the losses in the inverter.

The positive active vector is applied to the load by turning on $\mathrm{S} 1$ and S4, as shown in Fig. 3.

The negative active vector is done similarly, but in this case, $\mathrm{S} 2$ and $\mathrm{S} 3$ are turned on.

As shown in Fig. 4, the zero-voltage state is achieved by short circuiting the output of the inverter for the case of the unipolar switching pattern. The waveforms for this case are detailed in Fig. 5, and it can be seen that the output voltage has three levels: $+\mathrm{V}, 0$, and $-\mathrm{V}$ due to the unipolar switching pattern.

As shown in Fig. 6, in the case of a transformerless PV system using this type of topology and modulation, the highfrequency common-mode voltage, measured across $C_{\mathrm{G}-\mathrm{PV}}$, will lead to a very high leakage ground current, making it unsafe and therefore not usable (recommended) for transformerless PV applications. 


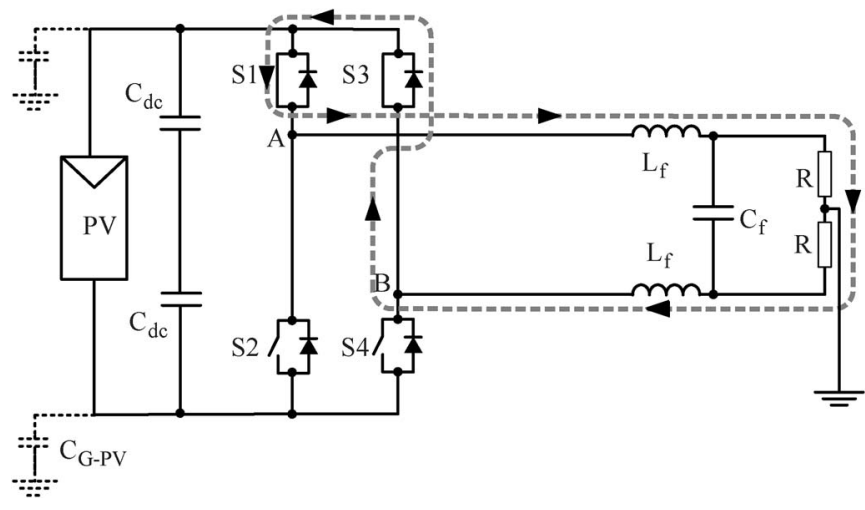

Fig. 4. HB-Unip topology: Zero vector applied to load, using S1 and S3 for positive voltage.
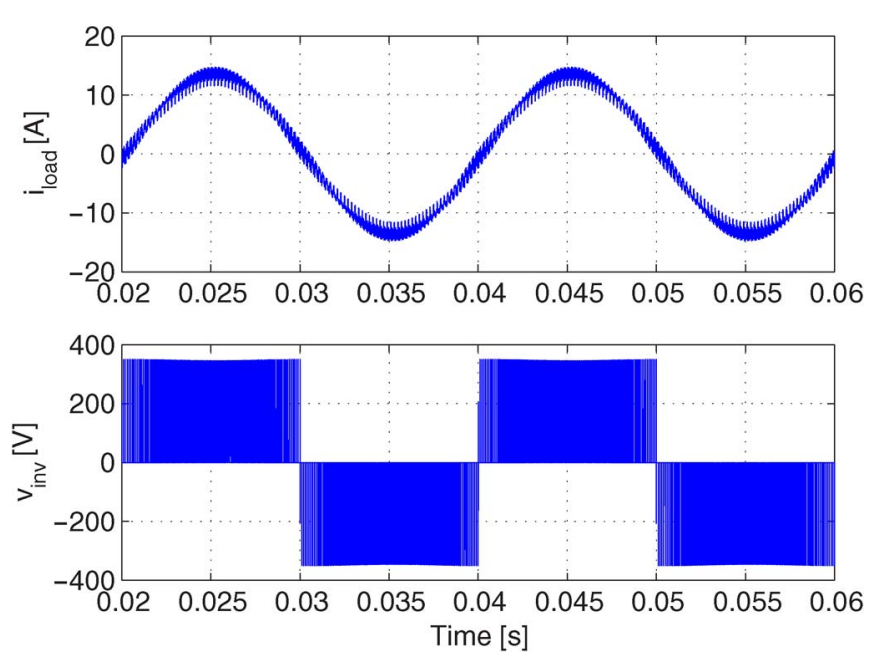

Fig. 5. HB-Unip topology: Load current and inverter output voltage.
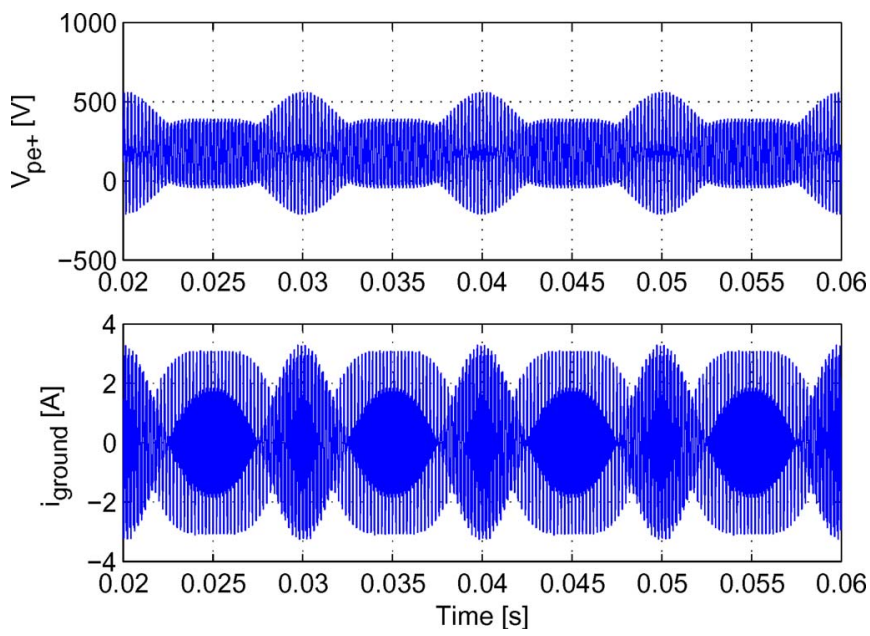

Fig. 6. HB-Unip topology: Voltage to ground and ground leakage current.

\section{B. HERIC}

This topology, shown in Fig. 7, combines the advantages of the three-level output voltage of the unipolar modulation with the reduced common-mode voltage, as in the case of bipolar modulation. This way, the efficiency of the inverter is

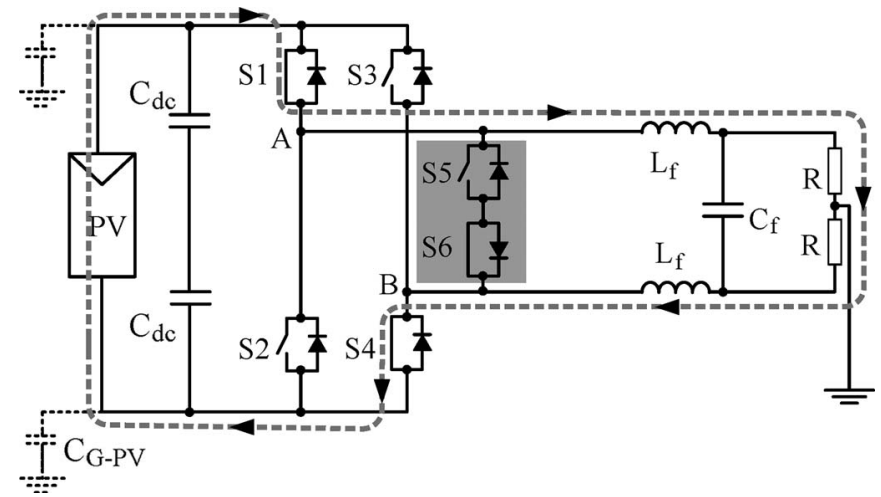

Fig. 7. HERIC topology: Active vector applied to load, using S1 and S4 during positive half-wave.

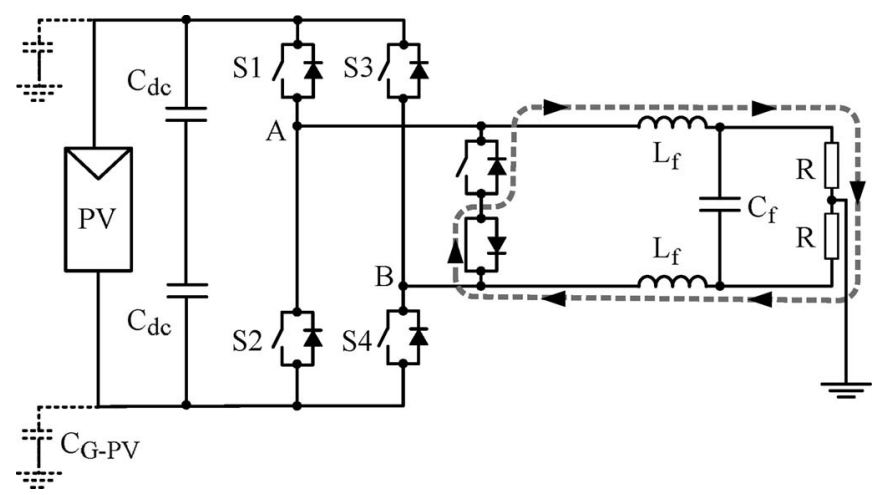

Fig. 8. HERIC topology: Zero vector applied to load, using S6 during positive half-wave.

increased, without compromising the common-mode behavior of the whole system.

The zero-voltage state is realized using a bidirectional switch shown with a gray background in Fig. 7. This bidirectional switch is made up of two insulated-gate bipolar transistors (IGBTs) and two diodes (S5 and S6). During the positive halfwave of the load (grid) voltage, S6 is switched on and is used during the freewheeling period of S1 and S4. On the other hand, during the negative half-wave, S5 is switched on and is used during the freewheeling period of S2 and S3 [12].

This way, using S5 or S6 as shown in Fig. 8, the zero-voltage state is realized by short-circuiting the output of the inverter, during which period the $\mathrm{PV}$ is separated from the grid, because $\mathrm{S} 1-\mathrm{S} 4$ or $\mathrm{S} 2-\mathrm{S} 3$ are turned off.

As shown in Fig. 9, the output voltage of the inverter has three levels and the load current ripple is very small, although, in this case, the frequency of the current is equal to the switching frequency. As shown in Fig. 10, the inverter generates no common-mode voltage; therefore, the leakage current through the parasitic capacitance of the PV would be very small.

\section{Proposed Topology $(H B-Z V R)$}

Another solution for generating the zero-voltage state can be done using a bidirectional switch made of one IGBT and one diode bridge. The topology is detailed in Fig. 11, showing the bidirectional switch as an auxiliary component with a gray background. This bidirectional switch is clamped to the 

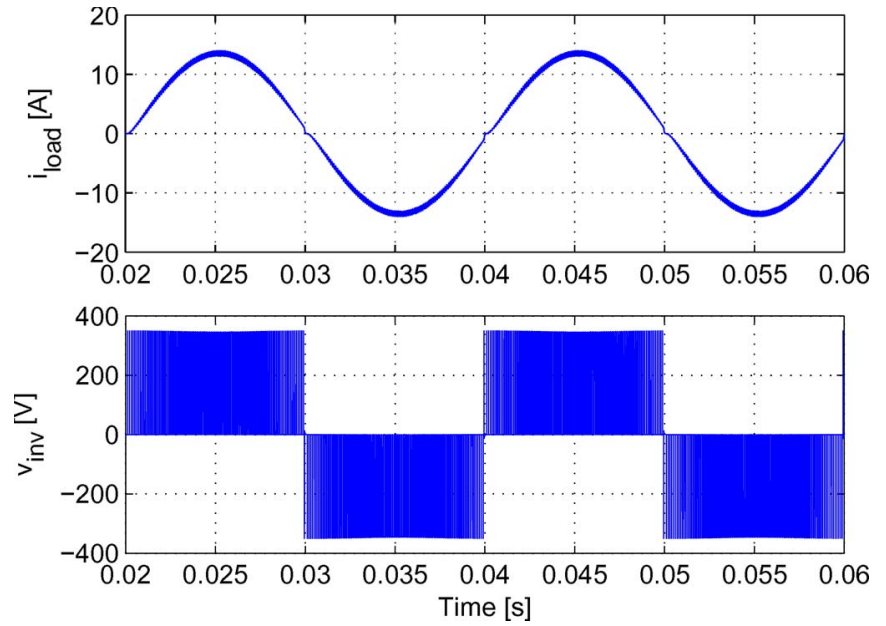

Fig. 9. HERIC topology: Load current and inverter output voltage.
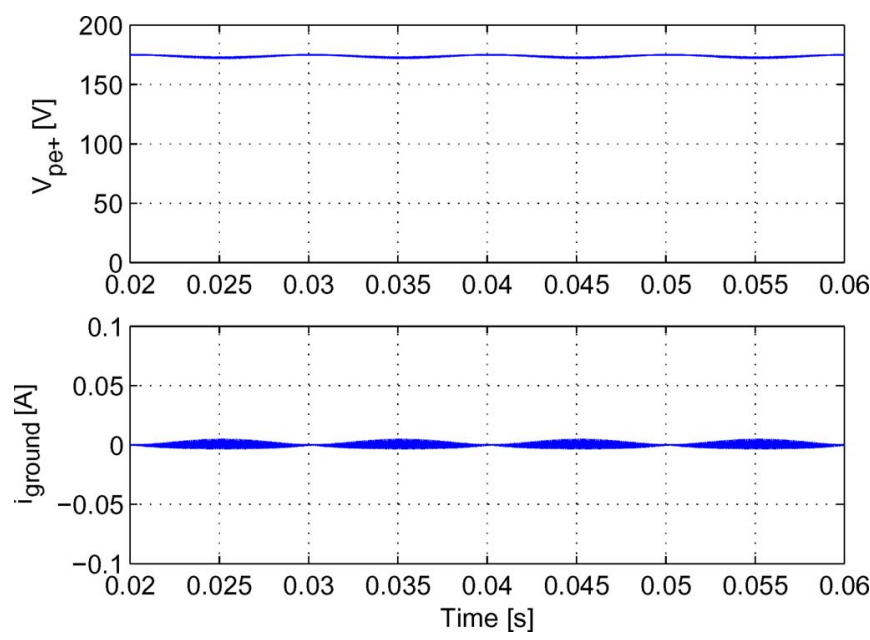

Fig. 10. HERIC topology: Voltage to ground and ground leakage current.

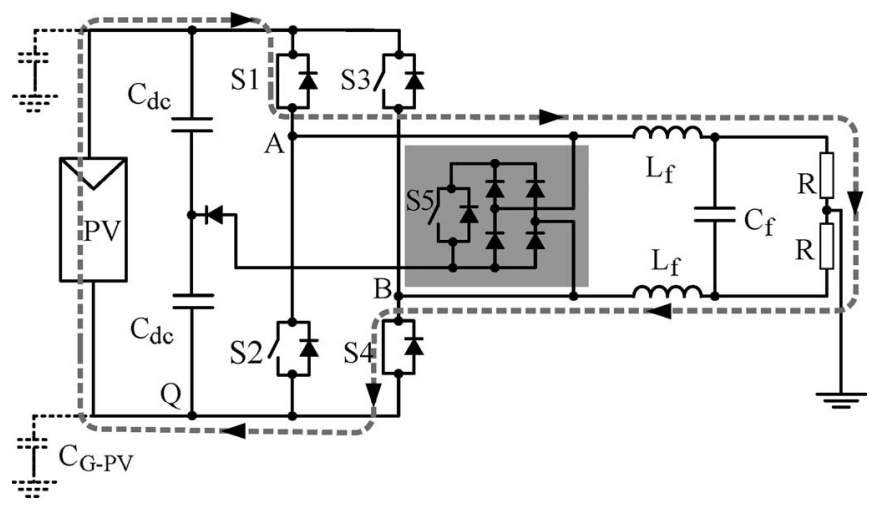

Fig. 11. HB-ZVR topology: Active vector applied to load, using S1 and S4 during positive half-wave.

midpoint of the dc-link capacitors in order to fix the potential of the PV array also during the zero-voltage vector when S1-S4 and $\mathrm{S} 2-\mathrm{S} 3$ are open. An extra diode is used to protect from short-circuiting the lower dc-link capacitor.

During the positive half-wave, S1 and S4 are used to generate the active state, supplying a positive voltage to the load, as shown in Fig. 11.

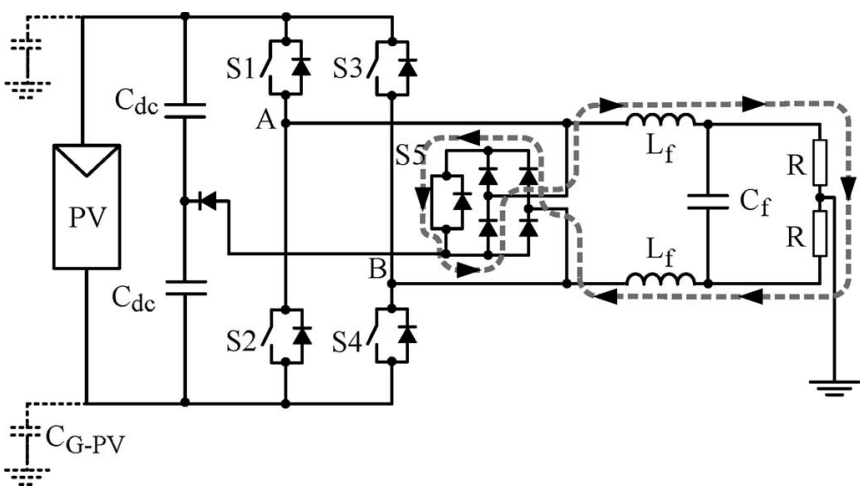

Fig. 12. HB-ZVR topology: Zero vector applied to load, using S5 during positive half-wave.

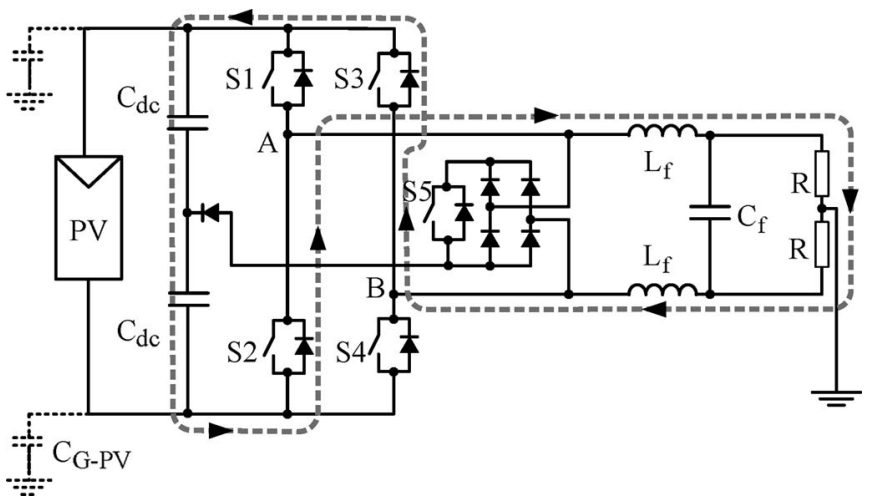

Fig. 13. HB-ZVR topology: Deadtime between turnoff of S1 and S4 and turnon of S5 during positive half-wave.

The zero-voltage state is achieved by turning on S5 when S1 and S4 are turned off, as shown in Fig. 12. The gate signal for S5 will be the complementary gate signal of S1 and S4, with a small deadtime to avoid short-circuiting the input capacitor. By using S5, it is possible for the grid current to flow in both directions; this way, the inverter can also feed reactive power to the grid, if necessary.

During the negative half-wave of the load voltage, S2 and S3 are used to generate the active vector and S5 is controlled using the complementary signal of S2 and S3 and generates the zerovoltage state, by short-circuiting the outputs of the inverter and clamping them to the midpoint of the dc-link.

During the deadtime, between the active state and the zero state, there is a short period when the freewheeling current finds its path through the antiparallel diodes to the input capacitor while all the switches are turned off. This is shown in Fig. 13 and leads to higher losses, compared to the HERIC topology, where the freewheeling current finds its path through the bidirectional switch, either through S5 or S6, depending on the sign of the current.

As shown in Fig. 14, the output voltage of the inverter has three levels, taking into account the freewheeling part during deadtime. In this case also, the load current ripple is very small and the frequency is equal to the switching frequency.

To show that this topology does not generate a varying common-mode voltage, $V_{\mathrm{cm}}$ has been calculated for the 

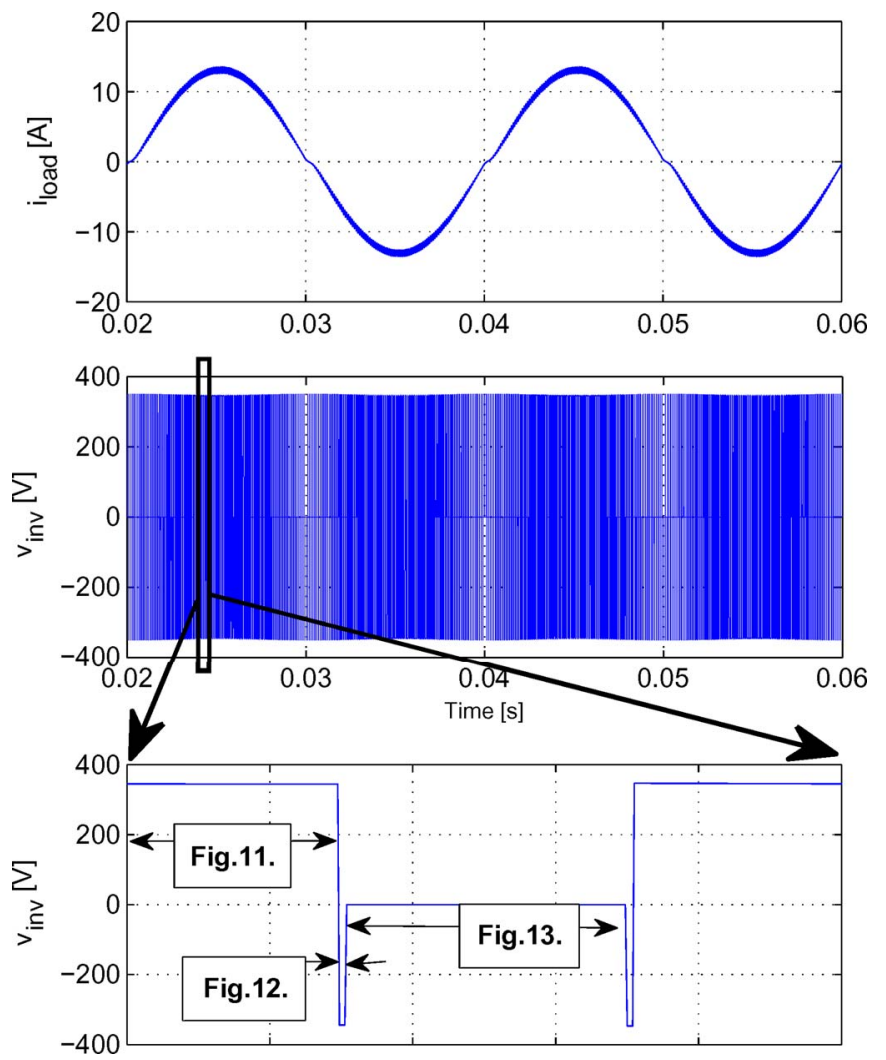

Fig. 14. HB-ZVR load current and inverter output voltage.

switching states regarding the positive, zero, and negative vectors

$$
\begin{aligned}
& V_{\mathrm{cm}}=\frac{V_{\mathrm{AQ}}+V_{\mathrm{BQ}}}{2} \\
& \text { Positive : } V_{\mathrm{AQ}}=V_{\mathrm{dc}} ; V_{\mathrm{BQ}}=0 \Rightarrow V_{\mathrm{cm}}=\frac{V_{\mathrm{dc}}}{2} \\
& \text { Zero }: V_{\mathrm{AQ}}=\frac{V_{\mathrm{dc}}}{2} ; V_{\mathrm{BQ}}=\frac{V_{\mathrm{dc}}}{2} \Rightarrow V_{\mathrm{cm}}=\frac{V_{\mathrm{dc}}}{2} \\
& \text { Negative : } V_{\mathrm{AQ}}=0 ; V_{\mathrm{BQ}}=V_{\mathrm{dc}} \Rightarrow V_{\mathrm{cm}}=\frac{V_{\mathrm{dc}}}{2} .
\end{aligned}
$$

As detailed by (1)-(4), the common-mode voltage is constant for all switching states of the converter. Therefore, the leakage current through the parasitic capacitance of the PV would be very small, as shown in Fig. 15.

\section{EXPERIMENTAL RESULTS}

In the case of the experimental results, the setup has the same parameters as was the case of the simulations: $V_{\mathrm{dc}}=350 \mathrm{~V}$, $C_{\mathrm{dc}}=250 \mu \mathrm{F}, L_{f}=1.8 \mathrm{mH}, C_{f}=2 \mu \mathrm{F}, F_{\mathrm{sw}}=8 \mathrm{kHz}$, and deadtime $=2.5 \mu \mathrm{s}$.

To compare the behavior of the different inverters, all three topologies have been tested using the same components. PM75DSA120 Intelligent Power Modules with maximum ratings of $1200 \mathrm{~V}$ and $75 \mathrm{~A}$ from Mitsubishi as IGBTs and DSEP 30-06BR with maximum ratings of $600 \mathrm{~V}$ and $30 \mathrm{~A}$ as diodes from IXYS have been used in the diode bridge of the proposed topology.
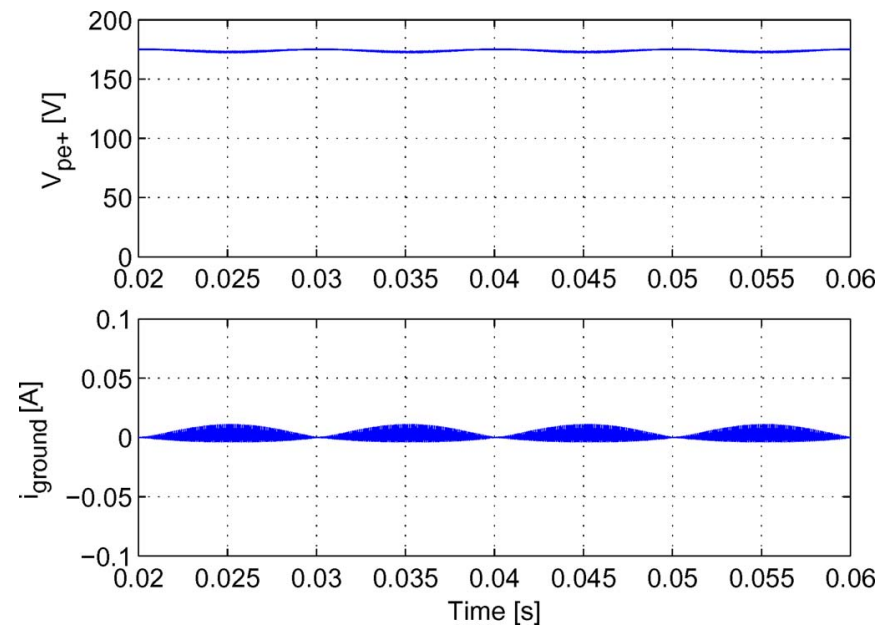

Fig. 15. HB-ZVR topology: Voltage to ground and ground leakage current.
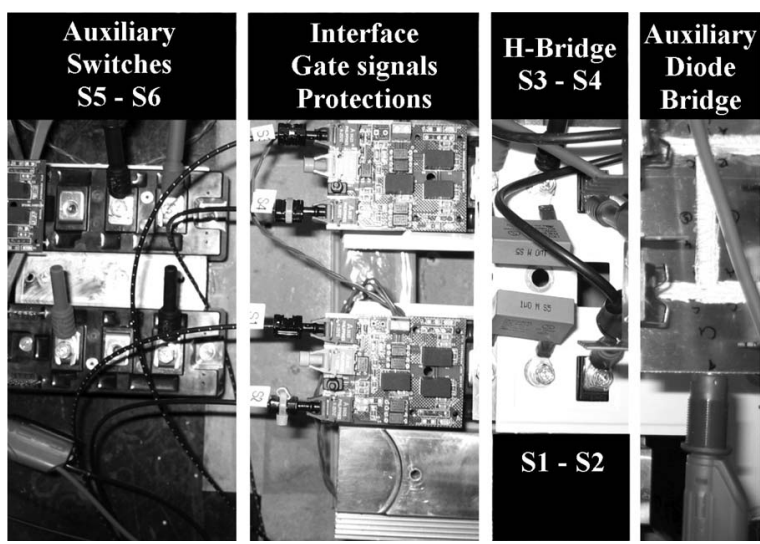

Fig. 16. Experimental setup: Modular solution.

The modular based setup shown in Fig. 16 makes it possible to test the different topologies, namely, full bridge with bipolar or unipolar modulation, the HERIC topology, and the proposed HB-ZVR, using the same components.

\section{A. HB With Unipolar Switching (Experiment)}

The main advantage of the HB inverter with unipolar switching is that the output voltage has three levels and the frequency of the output voltage is the double of the switching frequency, thereby increasing the efficiency of the inverter and decreasing the size of the output filter. However, the major drawback of this topology is the high-frequency common-mode voltage, which makes it unsuitable to be used for transformerless PV systems.

As shown in Fig. 17, the unipolar PWM strategy used in the case of the HB topology generates a high-frequency commonmode voltage, measured between the dc + terminal of the dc-link and ground, shown by channel 1 in Fig. 17.

As also shown in Fig. 17, the fast Fourier transform (FFT) represented by channel $M$ details the spectrum of the commonmode voltage. This common-mode voltage has very high amplitudes both at $\mathrm{dc}$ and the switching frequency. In addition, a low-frequency component can be seen on the measured voltage, which is caused by the $100-\mathrm{Hz}$ single-phase power variation. 


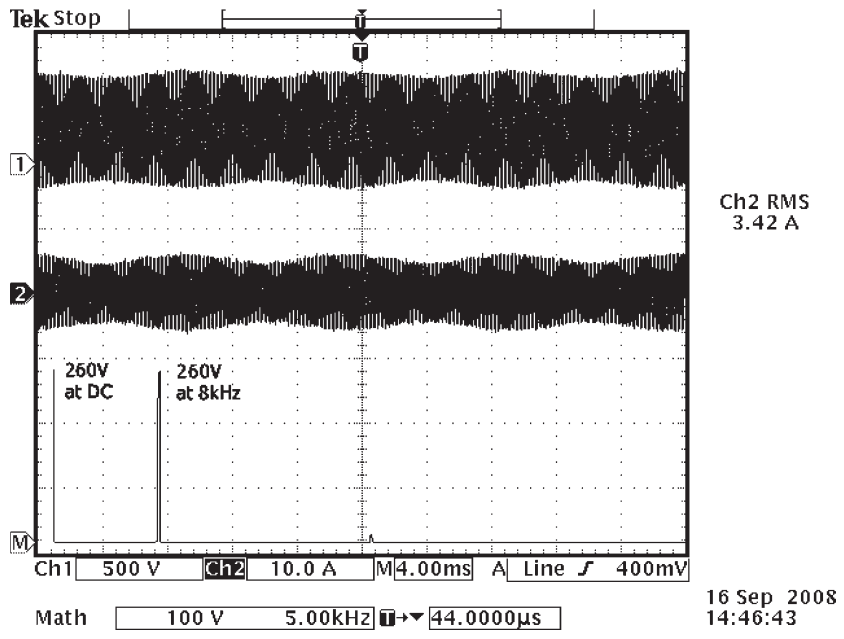

Fig. 17. Common-mode voltage (FFT) and ground current: FB-unipolar.

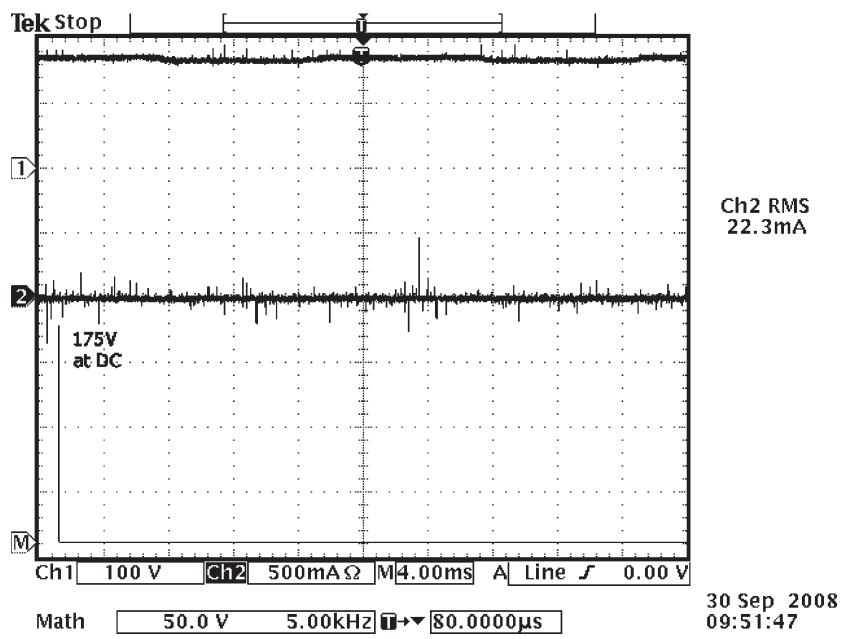

Fig. 18. Common-mode voltage (FFT) and ground current: HERIC.

This varying common-mode voltage generates a very high ground leakage current that is only limited by the parasitic capacitance of the PV array. In this case, the leakage current reaches to peaks of around $6 \mathrm{~A}$ as shown by channel 2 in Fig. 17.

\section{B. HERIC (Experiment)}

As presented in the simulation results (Section II-B), the HERIC topology generates a constant common-mode voltage, by disconnecting the PV from the load (grid) during the state of the zero vector, when the output of the inverter is short-circuited. This separation assures that the common-mode voltage acting on the parasitic capacitance of the PV array does not change in time, therefore keeping the leakage current at very low values, well below the standard requirement of $300 \mathrm{~mA}$, given by VDE-0126-1-1, the German standard for grid-connected PV systems.

As shown in Fig. 18, the voltage measured between the dc+ terminal of the dc-link and ground is constant and has no highfrequency content, represented by channel 1 on the scope. An FFT of channel 1 also shows only a dc component of the measured voltage.

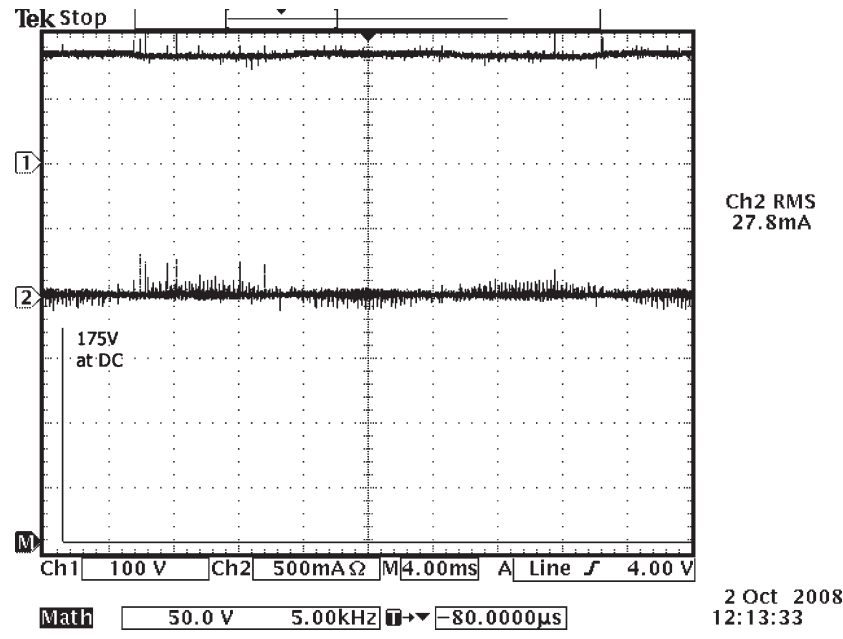

Fig. 19. Common-mode voltage (FFT) and ground current: HB-ZVR.

Furthermore, the leakage current, represented by channel 2 in the scope results in Fig. 18, is also very low, with an rms value of around $22 \mathrm{~mA}$.

\section{HB-ZVR (Experiment)}

As mentioned in Section II-C, the HB-ZVR topology generates the zero-voltage vector in a similar way as the HERIC topology, but using another solution for the bidirectional switch configuration. Of course, the common-mode behavior of the topology is similar, as was the case of the HERIC topology.

As shown in Fig. 19, the voltage measured between the $\mathrm{dc}+$ terminal of the dc-link and ground is constant and has no high-frequency content, represented by channel 1 on the scope picture. An FFT of this voltage also shows only a dc component without any high-frequency components.

In this case also, as detailed by channel 2 in the scope results in Fig. 19, the leakage current has also very low values, with an rms value of around $27 \mathrm{~mA}$.

\section{EFFICIENCY}

In the case of a single-phase grid connection, the required minimum dc-link input voltage of the inverter, in the European case, has to be at least $350 \mathrm{~V}$; otherwise, a boost stage is required. The tests have been done with an input voltage of $V_{\mathrm{dc}}=350 \mathrm{~V}$.

The HERIC topology, as also suggested by its name, has very high conversion efficiency throughout the whole working range and has the best efficiency within the compared topologies, as detailed in Table I and also shown in Fig. 20.

The HB-ZVR topology has a slightly lower efficiency, due to the fact that the bidirectional switch is controlled with the switching frequency, while in the case of the HERIC topology, the bidirectional switch is only switched with the mains frequency. With a maximum efficiency of $94.88 \%$, it is a very attractive solution for transformerless PV systems.

The HB-Bip topology has the lowest efficiency, due to the high losses as a result of the two-level voltage output.

The efficiency of the HB-Unip topology has not been included in the efficiency comparison of the transformerless 
TABLE I

EFFICIENCY AT DIFFERENT INPUT POWER With $V_{\mathrm{dc}}=350 \mathrm{~V}$

\begin{tabular}{|c|c|c|c|c|c|c|}
\hline & $500 \mathrm{~W}$ & $1000 \mathrm{~W}$ & $1500 \mathrm{~W}$ & $2000 \mathrm{~W}$ & $2500 \mathrm{~W}$ & $2800 \mathrm{~W}$ \\
\hline HB-Bip & $84,37 \%$ & $90,27 \%$ & $92,49 \%$ & $93,66 \%$ & $94,28 \%$ & $94,51 \%$ \\
\hline HERIC & $93,45 \%$ & $94,71 \%$ & $95,31 \%$ & $95,6 \%$ & $95,85 \%$ & $95,94 \%$ \\
\hline HB-ZVR & $90,38 \%$ & $92,79 \%$ & $93,78 \%$ & $94,39 \%$ & $94,76 \%$ & $94,88 \%$ \\
\hline
\end{tabular}

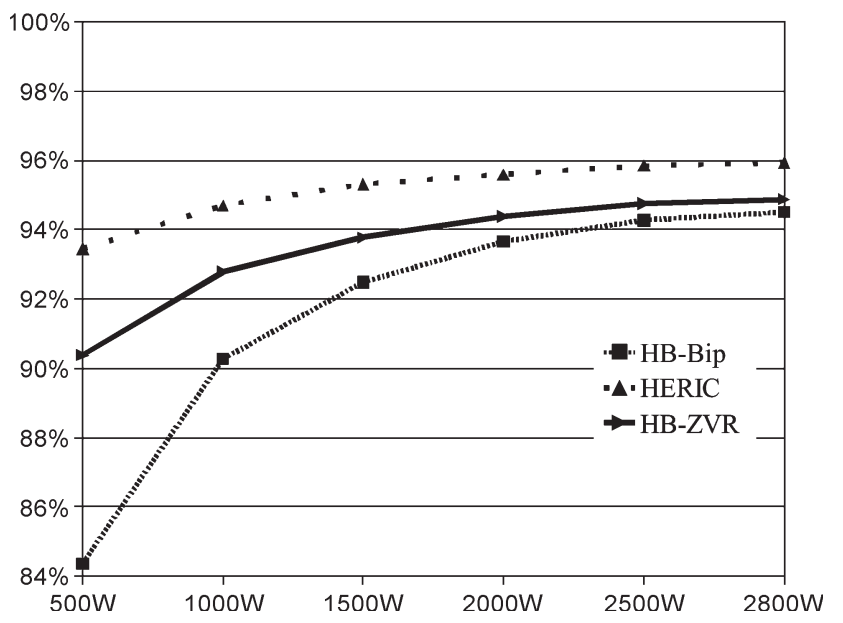

Fig. 20. Efficiency curve of the different topologies $\left(V_{\mathrm{dc}}=350 \mathrm{~V}\right)$.

topologies in Fig. 20 and Table I because of the influence of the galvanic isolation, where extra losses as high as $2 \%$ are possible due to the added transformer.

Nowadays, most PV inverters are current controlled, injecting only active power into the utility grid. In case there are many inverters injecting active power at the same time, the voltage at point of common coupling (PCC) might rise over the limits stated in the standards and trigger the safety of the inverters, leading to disconnection, or limit the power production below the available power. This leads to extra losses, because not all the available PV power is fed into the grid. In case PV inverters would have a P-Q implemented control, the aforementioned drawback could be dealt with by injection of reactive power, thereby controlling the voltage at PCC. Therefore, the capability of injecting reactive power would be a major advantage of future PV inverters, improving the total production of the PV system.

The advantage of HB-ZVR is that the HERIC topology, with the implemented PWM strategy, is only ideal for PV systems that supply the grid with active power, otherwise said to have the power factor: $\cos \varphi=1$. This is because the bidirectional switch of the HERIC topology made up of S5 and S6 is not controlled to be turned on simultaneously; therefore, current can only flow in a predefined direction, defined by the currently turned-on switch.

On the other hand, in the case of HB-ZVR, it does not matter what the sign the load current has, it will always find a path through the bidirectional switch, made up of a diode bridge and a switch. This makes it possible to have a reactive power flow that can be used to support the utility grid with additional services any time during the functioning of the inverter.

Disadvantage of HB-ZVR is the lower conversion efficiency, than it was in the case of the HERIC topology, due to the highfrequency switching pattern of the auxiliary switch S5, while in the case of the HERIC topology, S5 and S6 are switched with the grid frequency.

\section{CONCLUSiOn}

Transformerless inverters offer a better efficiency, compared to those inverters that have a galvanic isolation. On the other hand, in case the transformer is omitted, the generated common-mode behavior of the inverter topology greatly influences the ground leakage current through the parasitic capacitance of the PV.

Bipolar PWM generates a constant common-mode voltage, but the efficiency of the converter is low, due to the twolevel output voltage. By using unipolar PWM modulation, the output of the converter will have three levels, but in this case, the generated common-mode voltage will have high-frequency components, which will lead to very high ground leakage currents.

This paper has introduced a transformerless topology and given an alternative solution for the bidirectional switch, used to generate the zero-voltage state. The constant common-mode voltage of the HB-ZVR topology and its high efficiency make it an attractive solution for transformerless PV applications.

\section{REFERENCES}

[1] "Trends in photovoltaic applications: Survey report of selected IEA countries between 1992 and 2007," IEA, Paris, France, Rep. IEA-PVPS T1-T17, 2008.

[2] J. M. Carrasco, L. G. Franquelo, J. T. Bialasiewicz, E. Galvan, R. C. P. Guisado, M. A. M. Prats, J. I. Leon, and N. Moreno-Alfonso, "Power-electronic systems for the grid integration of renewable energy sources: A survey," IEEE Trans. Ind. Electron., vol. 53, no. 4, pp. 10021016, Jul. 2008.

[3] "Photon international," The Photovoltaic Magazine, Apr. 2007.

[4] R. Gonzalez, J. Lopez, P. Sanchis, and L. Marroyo, "Transformerless inverter for single-phase photovoltaic systems," IEEE Trans. Power Electron., vol. 22, no. 2, pp. 693-697, Mar. 2007.

[5] B. Sahan, A. N. Vergara, N. Henze, A. Engler, and P. Zacharias, "A singlestage PV module integrated converter based on a low-power currentsource inverter," IEEE Trans. Ind. Electron., vol. 55, no. 7, pp. 2602-2609, Jul. 2008.

[6] R. Gonzalez, E. Gubia, J. Lopez, and L. Marroyo, "Transformerless single-phase multilevel-based photovoltaic inverter," IEEE Trans. Ind. Electron., vol. 55, no. 7, pp. 2694-2702, Jul. 2008.

[7] J. Selvaraj and N. A. Rahim, "Multilevel inverter for grid-connected PV system employing digital PI controller," IEEE Trans. Ind. Electron., vol. 56, no. 1, pp. 149-158, Jan. 2009.

[8] E. Gubía, P. Sanchis, A. Ursúa, J. Lopez, and L. Marroyo, "Ground currents in single-phase transformerless photovoltaic systems," Prog. Photovolt., Res. Appl., vol. 15, no. 7, pp. 629-650, 2007.

[9] T. Kerekes, R. Teodorescu, and U. Borup, "Transformerless photovoltaic inverters connected to the grid," in Proc. APEC, Feb. 25-Mar. 1, 2007, pp. 1733-1737.

[10] T. Kerekes, R. Teodorescu, C. Klumpner, M. Sumner, D. Floricau, and R. Rodriguez, "Evaluation of three-phase transformerless photovoltaic inverter topologies," in Proc. Eur. Conf. Power Electron. Appl., Sep. 2-5, 2007, pp. 1-10.

[11] T. Kerekes, R. Teodorescu, and M. Liserre, "Common-mode voltage in case of transformerless PV inverters connected to the grid," in Proc. ISIE, Jun. 29-Jul. 1, 2008, pp. 2390-2395. 
[12] H. Schmidt, Ch. Siedle, and J. Ketterer, "Europeische Patentanmeldung," EP 1369985 A2.

[13] M. Victor, F. Greizer, S. Bremicker, and U. Huebler, "Europeische Patentanmeldung," EP 1369985 A2.

[14] D. Geibel, J. Jahn, and R. Juchem, "Simulation model based control development of a multifunctional PV-inverter," in Proc. 12th Eur. Conf. Power Electron. Appl., Sep. 2-5, 2007, pp. 1-10.

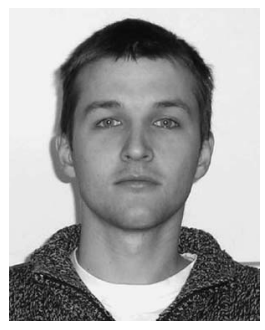

Tamás Kerekes (S'06-M'09) was born in Cluj-Napoca, Romania, in 1978. He received the Electrical Engineer Diploma with specialization in electric drives and robots from the Technical University of Cluj, Cluj-Napoca, Romania, in 2002 and the M.Sc. degree in the field of power electronics and drives from the Institute of Energy Technology, Aalborg University, Aalborg, Denmark, in 2005 , where he has been working toward the $\mathrm{Ph} . \mathrm{D}$. degree since September 2005. The topic of his Ph.D. program is "analysis and modeling of transformerless PV inverter systems."

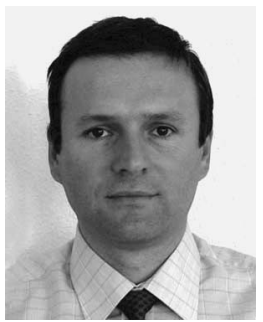

Remus Teodorescu (S'94-M'99-SM'02) received the Dipl.Ing. degree in electrical engineering from the Polytechnical University of Bucharest, Bucharest, Romania, in 1989 and the Ph.D. degree in power electronics from the University of Galati, Galati, Romania, in 1994.

Since 1998, he has been with the Power Electronics Section, Institute of Energy Technology, Aalborg University, Aalborg, Denmark, where he is currently a Full Professor. He is the Founder and Coordinator of the Green Power Laboratory, Aalborg University, where he is focusing on the development and test of grid converters for renewable energy systems. He is also the Coordinator of the Vestas Power Program. He has more than 120 papers published, one book, and three patents (pending). His areas of interest are in design and control of power converters used in renewable energy systems, distributed generation of mainly wind power and photovoltaics, computer simulations, and digital control implementation.

Dr. Teodorescu is an Associate Editor for the IEEE POWER ELECTRONICS LETTERS and the Chair of the IEEE Danish Joint Industrial Electronics Society/Power Electronics Society/Industry Applications Society (IAS) Chapter. He is the corecipient of the Technical Committee Prize Paper Awards at the 1998 IEEE IAS Annual Meeting and the Third-ABB Prize Paper Award at the 2002 IEEE Optim.

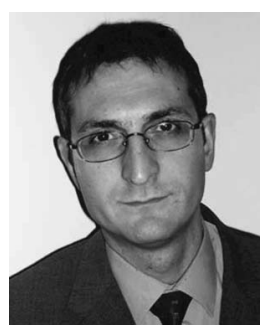

Pedro Rodríguez (S'99-M'04) received the B.S. degree in electrical engineering from the University of Granada, Granada, Spain, in 1989, and the M.S. and $\mathrm{Ph} . \mathrm{D}$. degrees in electrical engineering from the Technical University of Catalonia (UPC), Barcelona, Spain, in 1994 and 2004, respectively.

In 1990, he joined the faculty of UPC, as an Assistant Professor, where he is currently an Associate Professor. In 2005, he was a Visiting Researcher with the Center for Power Electronics Systems, Virginia Tech, Blacksburg. In 2006 and 2007, he was a Postdoctoral Researcher with the Institute of Energy Technology, Aalborg University (AAU), Aalborg, Denmark, where he has taught Ph.D. courses since 2006. He is currently the Head of the Research Group on Renewable Electrical Energy Systems at the UPC and a Cosupervisor of the Vestas Power Program in partnership collaboration with the AAU. He has coauthored about 100 papers in technical journals and conferences. He is the holder of four patents. His research interest is focused on applying power electronics to distributed energy systems and power quality.

Dr. Rodríguez is a member of the IEEE Power Electronics, IEEE Industrial Electronics, and IEEE Industry Application Societies.

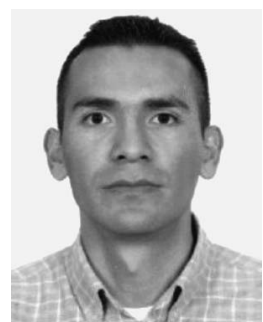

Gerardo Vázquez (S’07) was born in México in 1977. He received the B.Sc. degree in electronic engineering from the Technical Institute of Apizaco, Tlaxcala, México, in 2003 and the M.S. degree in electronic engineering from the National Center of Research and Technological Development, Cuernavaca, México, in 2006. He is currently working toward the Ph.D. degree in electrical engineering at the Technical University of Catalonia (UPC), Barcelona, Spain.

Since 2006, he has been a Researcher with the Department of Electrical Engineering, UPC. His research interests include power converters and control for nonconventional energy sources.

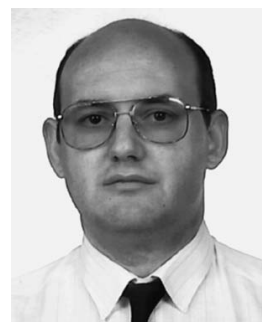

Emiliano Aldabas (S'97-A'99-M'04) was born in Teruel, Spain, in 1964. He received the M.Eng. degree in electrical engineering and the Ph.D. degree from the Technical University of Catalonia (UPC), Terrassa, Spain, in 1992 and 2002, respectively.

In 1993, he joined the Department of Electronic Engineering, UPC, as an Assistant Professor, where he was a Lecturer from 1998 to 2007. Since 2008, he has been an Associate Professor with the Department of Electrical Engineering, UPC, Barcelona, Spain. $\mathrm{He}$ is currently a Member of the Electrical Engineering Research Group, UPCÈs Terrassa Campus, and EduQTech Group. His research interests include power electronics, modulation, current controllers, adjustable-speed drives, and high-performance drive systems, particularly, hysteresis current controllers for power inverters, on which topic he has authored several technical papers.

Dr. Aldabas is a member of the IEEE Industrial Electronics, IEEE Power Electronics, and IEEE Education Societies. 